\title{
Bases históricas da Epidemiologia
}

* Departamento de Medicina Pre. ventiva da UFBA.
Naomar de Almeida Filho*

$O$ presente ensaio tenta sistematizar uma série de informações esquemáticas sobre a história da Epidemiologia, a fim de compreender a sua evolução enquanto disciplina articulada ao desenvolvimento histórico dos principais movimentos sociais na área da saúde. Discute-se as raizes da Epidemiologia a partir do tripé Clinica-EstatisticaMedicina Social, o seu desenvolvimento inicial subsidiário à Saúde Pública, a sua constituição ideológica e o seu avanço técnico no bojo do projeto preventivista.

Finalmente, a Epidemiologia moderna é vista como uma disciplina que retorna às suas raizes históricas e politicas no movimento da Saude Coletiva, opondo-se, a nivel teórico, às pressões para torná-la um mero instrumento "método-lógico"da pesquisa clínica.

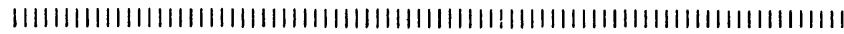

A primeira medicina do coletivo é a Medicina Veterinária. Foucault ${ }^{5}$ nos conta que a Academia de Medicina de Paris, fundadora da Clínica moderna no século XVII, organiza-se a partir da Ordem Real para que os médicos estudassem a epidemia que periodicamente dizimava o rebanho ovino, com graves perdas para a nascente indústria textil francesa. Pela primeira vez, conta-se doenças no esforço de sua eliminação. Foucault não nos diz se os insignes doutores obtiveram algum resultado. $O$ fato é que, em se tratando de humanos, a "ciência clínica" começa reforçando mais ainda o estudo do unitário, o caso.

No âmbito político, o século XVII testemunha o aparecimento do Estado moderno. Especificam-se os conceitos de Estado, Governo, Nação e Povo. A idéia de que a riqueza principal de uma nação é o seu povo, aliada ao dado objetivo de que o poder político é o poder dos exércitos, faz com que seja necessário contar o povo e o exército, ou seja, o Estado. A medida do Estado, a Estatística, o povo como elemento produtivo, o exército como elemento beligerante, precisam não apenas do número mas também da disciplina e da saúde. Estas são as bases da "aritmética política" de William Petty (1623-1697) e dos levantamentos pioneiros da "Estatística Médica de John Graunt (1620-1674) ${ }^{8}$.

Durante o século XVII, o poder político da burguesia emergente cc.ısnlida-se pela "restauração", como na InglaCadernos de Saúde Pública, R.J., 2 (3): 304-311, jul/set, 1986.
Recebido para publicação em 06.03 .85 
terra e Alemanha, ou pela "revolução", como na França e nos Estados Unidos. Diferentes tipos de intervençao estatal sobre a questão da saúde das populações ocorrem no período. Na Inglaterra, o "movimento hospitalista" e o assistencialismo antecedem uma medicina da força de trabalho já parcialmente sustentada pelo Estado em áreas urbanas. Na França, com a Revolução de 1789, implanta-se uma "medicina urbana" a fim de sanear os espaços das cidades, disciplinando a localização de cemitérios e hospitais, arejando as ruas e construções públicas $e$ isolando áreas "miasmáticas"5. Na Alemanha, Johann Peter Franck (1745-1821) sistematiza as propostas de uma "Política Médica", baseada na compulsoriedade de medidas de controle e vigilância das doenças, sob a responsabilidade do Estado, junto com a imposição de regras de higiene individual para o povo ${ }^{14}$.

Em 1825, P.C. Alexandre Louis (1787-1872) publica em Paris um estudo estatístico de 1960 casos de tuberculose. Médico e matemático, Louis é também o percursor da avaliação de eficácia dos tratamentos clínicos utilizando os métodos da Estatística ${ }^{17}$. A abordagem de doenças pelo "método numérico" influencia o desenvolvimento dos primeiros estudos de morbidade na Inglaterra e nos Estados Unidos, origem da Saúde Pública ${ }^{9}$. Alguns dos discípulos de Louis iniciam o movimento da Medicina Social na França.

A Revolução Industrial e sua economia política trazem o fato e a idéia da força de trabalho. A formação de um proletariado urbano, submetido a intensos níveis de exploração, expressa-se como luta política sob a forma de diferentes socialismos, ditos utópicos porque iniciais. O desgaste da classe trabalhadora deteriora profundamente as suas condições de saúde, conforme mostra Friedrich Engels em seu "As Condições da Classe Trabalhadora na Inglaterra em 1844", talvez o primeiro texto analítico da epidemiologia crítica. Um dos socialismos passa a interpretar a política como medicina da sociedade e a medicina como prática política. Desde então, o termo Medicina Social, proposto por Guèrin em 1838, serve para designar genericamente modos de tomar coletivamente a questão da saúde. Mas o projeto original da Medicina Social morre nas barricadas da Comuna de Paris de 1848. Também Engels não pretendia ser médico, e muito menos inaugurar a Epidemiologia.

A descoberta dos microorganismos causadores de doença representa um inegável fortalecimento da medicina organicista. As doenças mais prevalentes na época, de natureza infecto-contagiosa, favorecem a hegemonia de tal modo interpretativo. Mais uma vez o individual, agora cientificizado, suplanta o coletivo na abordagem da doença e seus determinantes. Não deixa de ser irônico que os pioneiros 
* Em um certo sentido, é possivel dizer que a Epidemiologia nasceu com Hipócrates. Os seus escritos sobre a epilepsia e sobre a morbidade entre os citados sem dúvida antecipam o chamado racici ínio epidemiológico ${ }^{10}$. Porém a tradição esculapiana fez questão de sufocar o espírito da primazia do coletivo, base da democracia da polis ateniense, também influente na Ilha de Cós. Os herdeiros de Hipocrates voltaram-se para o individualismo a fim de fundamentar a supremacia da sua prática frente ds dezenas de seitas que, no Mundo Antigo, prometiam a saude para o homem $^{3}$. Nesse sentido a Epidemiologia também morreu com Hipocrates. estudos de John Snow (1813-1858), considerado o pai da Epidemiologia, tenham se iniciado no contexto da Medicina Social, para terminar antecipando uma demonstração da teoria microbiana, no caso da transmissão do cólera morbo ${ }^{2}$.

O termo Epidemiologia, segundo Najera ${ }^{11}$, havia sido cunhado por Juan de Villalba, em 1802, mais no sentido de um histórico das epidemias espanholas. Em 1950, organizase na Inglaterra a London Epidemiological Society, fundada por jovens médicos simpatizantes das idéias médico-sociais. Porém o notável trabalho de William Farr, que em 1839 criara um registro anual de mortalidade e morbidade para a Inglaterra e País de Gales, marca a institucionalização da Estatística Médica ${ }^{8}$.

Assim, a versão britânica da Medicina Social desliza por uma vertente técnica, constituindo a chamada Saúde Pública. $\mathrm{O}$ conhecimento básico sobre as doenças transmissíveis cresce muito rapidamente, monopolizando o avanço do conhecimento epidemiológico, dirigindo-o para os processos de transmissão ou controle das epidemias então prevalentes. Data dessa época o ensino dos primeiros conhecimentos sobre distribuição de doenças em populações nos programas de saúde pública. Também remonta a esse período a prática da Saúde Pública, e sua incipiente Epidemiologia, como uma "medicina social" do colonialismo. O controle da varíola, malária, febre amarela e outras doenças ditas "tropicais" nos portos dos países colonizados distingue essa fase, que tem como características principais um intenso pragmatismo e um atrelamento da Saúde Pública às ciências básicas da área médica. Talvez por essas razões, há um retardamento no processo de constituição da Epidemiologia enquanto disciplina autônoma. Para se desvencilhar do projeto sanitarista, a Epidemiologia precisa então retomar a tradição hipocrática e médico-social de privilegiamento do coletivo, visto como mais que um conjunto de indivíduo. ${ }^{*}$

A saída para tal impasse metodológico é também inicialmente técnica. Afinal, dispunha-se do avanço independente da Estatística, que apresenta a novidade da teoria das Probabilidades. Major Geenwood (1888-1949), primeiro professor de Epidemiologia na London School of Hygiene and Tropical Medicine, é o principal responsável pela introdução do raciocínio estatístico na investigaçao epidemiológica, rejeitando o caráter fundamentalmente descritivo da "epidemiologia das epidemias". Os trabalhos de Wade Hampton Frost (1880-1938) pela primeira vez utilizam técnicas estatísticas para o estudo das variações na incidência e prevalência das doenças, com a intenção de avaliar os seus determinantes genéticos e sociais.

As investigações de Goldberger (1874-1927) sobre a pelagra que, nos idos de 1915, estabelecem a sua natureza carenCadernos de Saúde Pública, R.J., 2 (3): 304-311, jul/set, 1986. 
cial a partir do uso do raciocínio epidemiológico, registram a expansão da disciplina para um objeto mais ampliado, para além das doenças infecto-contagiosas. Entretanto, o primeiro aporte sistemático ao conhecimento epidemiológico, "The Principles of Epidemiology"16, escrito no final dos anos 20, ainda se refere exclusivamente às doenças infecciosas. Além da expansão do objeto proposto epidemiológico, busca-se uma saída conceitual para o impasse da ideologia teórica da Medicina. É justamente um epidemiologista, John Ryle (1889-1950), quem sistematiza o paradigma da História Natural das Doenças em 1936.

A crise da medicina "científica" eclode na década de 30. $\mathrm{O}$ avanço tecnológico da prática médica determina uma redução do seu alcance social. A fragmentação do cuidado médico conduz à especialização, à ênfase em procedimentos complementares, a uma elevação de custos e finalmente à capitalização da assistência à saúde. Isto ocorre justamente quando o sistema político do capitalismo, em crise, mais necessita da saúde enquanto mecanismo de controle social. A crise das sociedades capitalistas ocidentais revela então uma incapacidade do sistema econômico monopolista em prover condições mínimas de vida e saúde para a totalidade das suas populações. Neste cenário, redescobrem o caráter social e cultural da enfermidade e da medicina, bem como as suas articulações com a estrutura e a superestrutura da sociedade. Busca-se a consolidação de um discurso sobre o social capaz de dar conta dos processos culturais, econômicos e políticos que pareciam levantar resistências à competência técnica da medicina". O "retorno triunfante" do social se faz pelo recurso à Epidemiologia, supostamente despojada da politização assumida pelo movimento da Medicina Social. Além disso, o desenvolvimento da disciplina a atrai para o padrão positivista das ciências do homem, espelhando-a no modelo da Biologia. À Fisiologia Humana, que se aplica aos processos normais do organismo, contrapõe-se à Demografia, encarregada dos processos normais da sociedade, qual verdadeira "fisiologia social". À Fisiopatologia, que se detém sobre os processos patológicos do organismo, corresponde à Epidemiologia. Destinada ao estudo dos processos patológicos na sociedade, tomada como uma "patologia social" (em um sentido diferente daquele proposto pela teoria dos problemas sociais - conforme indica Davis ${ }^{4}$, a Epidemiologia seria essencialmente positivista. Mesmo a partir dessa perspectiva inicial, é claro que será sempre redundante qualquer referência a uma "epidemiologia social".

A organização dos exércitos para a Segunda Guerra Mundial levanta a questão da saúde física e mental dos combatentes, e representa uma demanda concreta para o desenvol-
As diferentes formações ideológicas que se sucederam (helenismo, cristianismo, feudalismo) não propiciaram condições para uma medicina do coletivo. Os médicos "ecléticos" de Roma, modelados na figura de Galeno (230-201 A.C.) eram antes de tudo receitadores de muitos medicamentos para poucos doentes. No inicio da Idade Média, as invasões dos bdr. baros trouxeram um predominio de práticas de caráter mágicoreligioso. Amuletos, orações e cultos a santos protetores da saúde materializavam a ideologia religiosa, caracteristicamente medieval, de salvação da alma e danação do corpo individual: a Igreja tem horror ao sangue ${ }^{17}$. Mesmo a medicina árabe, que preservou os textos de Hipócrates durante a época medieval, exercia uma prática voltada para o individuo. 
vimento de métodos mais eficientes para medi-la. $O$ aperfeiçoamento de tais métodos resulta na possibilidade de sua aplicação a populaçoes civis. Essa fase, que coincide com um pós-guerra associado a intensa expansão do sistema econômico capitalista, caracteriza-se pela realização de grandes inquéritos epidemiológicos, principalmente a respeito de doenças não-infecciosas, que haviam se revelado como problemas de saúde pública durante o processo de seleção de recrutas para os exércitos.

Notadamente nos Estados Unidos, a Medicina Preventiva consolida-se como movimento ideológico, o que leva à instalação de departamentos específicos em escolas médicas. $\mathrm{Na}$ Europa Ocidental, onde o pós-guerra propicia o estabelecimento dos chamados welfare states, a assistência à saúde integra-se mais claramente às políticas sociais, prescindindo de formulações mais visivelmente ideológicas para a consolidação do discurso do social na medicina. Nesses países, fala-se, ensina-se e pratica-se uma versão da Medicina Social atualizada pela democracia social. Em ambos os casos, a Epidemiologia impõe-se aos programas de ensino médico e de saúde como um dos setores da pesquisa médico-social mais dinâmicos e frutíferos. Aparece uma clara hegemonia do conhecimento epidemiológico em relação às outras disciplinas da Medicina Preventiva. O processo de institucionalização da disciplina culmina com a fundação da International Epidemiological Association em 1954 ${ }^{7}$. As ciências sociais aplicadas à saúde experimentam um esgotamento após a contribuição da sociologia médica parsoniana, e a administração de saúde passa por uma crise de identidade, questionada pelo avanço do estudo das instituições e pelo desenvolvimento do nascente planejamento social.

Novos modelos teóricos são propostos para dar conta dos impasses sofridos pela teoria unicausalista de doença, aperfeiçoando o paradigma da História Natural das Doenças. Emerge uma forte tendência "ecológica" na Epidemiologia, com uma versão "ocidental" 12 , contraposta à versão soviética $^{13}$. Nessa época, década de 50 , programas de pesquisa departamentos de Epidemiologia experimentam febrilmente novos ou aperfeiçoados desenhos de pesquisa. A partir daí, estabelecem-se as regras básicas da análise epidemiológica, sobretudo pela fixação dos indicadores típicos da área (incidencia e prevaléncia) e pela delimitação do conceito de risco, fundamental para a adoção da Bioestatística como instrumental analítico de escolha. Acontecem nesse período, ainda, o desenvolvimento de técnicas de identificação de casos (em praticamente todos os setores da Medicina), adequados à aplicação em grandes amostras, e a descrição dos principais tipos de "bias" na investigação epidemiológica ${ }^{15}$. 
No in ício dos anos 60 , a pesquisa epidemiológica experimenta a mais profunda transformação da sua curta história, com a introdução da computação eletrônica. À ampliação real dos bancos de dados, soma-se à potencialidade, obviamente ainda não esgotada, de criação de técnicas analíticas com especificações inimagináveis no tempo da análise mecânica de dados. As análises multivariadas trazem uma perspec. tiva de solução do problema das variáveis confundíveis, intrínseco aos desenhos observacionais que praticamente determinam a especificidade da Epidemiologia em relação às demais ciências básicas da área médica ${ }^{10}$. Também a computação torna possível a realização de pareamentos múltiplos, estratificação de variáveis confundíveis, sumarização de efeito-modificação e controle de "bias", entre outros mais complexos, além de propiciar o aperfeiçoamento e a disponibilidade de testes de significância estatística cada vez mais precisos e poderosos. Nessa fase, deve-se destacar a a contribuição de Jerome Cornfield (1912-1979) para o desenvolvimento de estimativas de risco relativo, além de introduzir técnicas de regressão logística na análise epidemiológica ${ }^{8}$. Porém a Epidemiologia dos anos 60 não é somente aperfeiçoamento de tecnologia para análise de dados. Há também um forte movimento de sistematização do conhecimento epidemiológico produzido, talvez melhor exemplificado pela obra de John Cassel (1915-1977) no sentido da integração dos modelos biológicos e sociológicos em uma teoria compreensiva da doença, unificada pelo "toque" da Epidemiologia.

A tendência à matematizaçao da Epidemiologia recebe um reforço considerável na década seguinte. Modelos matemáticos de distribuição de inúmeras doenças são então propostos $^{6}$. O campo da Epidemiologia encontra, assim, identidade provisória, justificando a consolidação da sua autonomia enquanto disciplina. Impõe-se na pesquisa sobre a saúde/doença com o recurso à Matemática. Para a Epidemiologia, a Matemática serve ideologicamente como um poderoso mito de razão, indispensável para o confronto com a "experiência clinica" ou a "demonstração experimental" enquanto supostos fundamentos da pesquisa médica. Resulta que, afinal, os epidemiologistas também se afirmam como metodólogos da investigação na área médica, abrindo a possibilidade de uma "epidemiologia clínica" regredida à negação do caráter social da disciplina. Aliás, já em 1938, John Paul antecipava tal proposta, ignorada pela investigação médica da época, possivelmente devido ao estado do conhecimento epidemiológico no período, ainda carente de um mito de razão suficientemente prestıgiado ${ }^{18}$.

Nos países do Terceiro Mundo, a incorporação do conhecimento epidemiológico vem se fazendo de modo cada vez 
mais acelerado. Nos incipientes centros de produção científica desses países, é evidente o predomínio de uma postura marcadamente mais politizada, conquistando espaços ao tradicionalismo herdado do sanitarismo colonialista. Os programas da UAM no México, do CEAS no Equador e alguns centros de pós-graduação no Brasil são exemplos, na América Latina, dessa busca de uma Epidemiologia de acordo com os princípios teóricos da Medicina Social e mais adequada à realidade desses países. Essa linha de abordagem da questão poderia ser provisoriamente designada de "epidemiologia crítica".

No momento atual, a Epidemiologia inegavelmente retoca o seu reconhecimento enquanto campo científico. Simultaneamente, busca o estabelecimento do objeto epidemiológico, à medida em que amplia o seu âmbito de ação e institucionaliza-se como prática de pesquisa. Tal projeto tem sido relativamente bem sucedido às custas de uma cooptação dos princípios de determinação da disciplina. Entretanto, trata-se de um processo em curso, desigual no seu desenvolvimento em formações sociais distintas. Mesmo nos países centrais, onde a Epidemiologia atinge tal fase de consolidação cooptada, não se pode falar realmente em um desligamento dos princípios médico-sociais. Na medida em que as contradições das respectivas formações sociais inevitavelmente se refletem sobre a estrutura acadêmica e de financiamento à pesquisa desses países, impõe-se uma abertura para a discussão crítica dos temas da Epidemiologia.

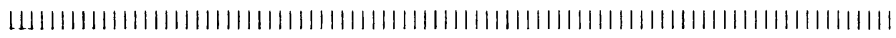

The present article is an attempt to organize some information about the history of Epidemiology, in order to understand its evolution as a scientific discipline connected with the historical development of major social movements in the health fields. The roots of Epidemiology from the triad Clinics-Statistics-Social Medicine, its initial development depending on the Public Health, its Technical advancement and ideological constitution within the preventive project, are all discussed. Finnally, modern Epidemiology is seen as a discipline that recovers its historical and roots through the movement of Collective Health, in opposition, at a theorctical level, to pressures to make it a mere "methodological" tool for clinical research.

\section{REFERÊNCIAS BIBLIOGRÁFICAS}

1. AROUCA, A.S. O dilema preventivista. São $P_{\text {c }}$ lo. 1975. (Tese de Doutorado, UNICAMP). 
2. CAMERON, D. \& JONES, G. John Snow, the Broad street pump and modern epidemiology. Int. J. Epidemiol., 12: 396-3, 1983.

3. ClAVREUIL, J. A ordem médica. São Paulo, Brasiliense, 1983.

4. DAVIS, N. Sociological constructions of deviance. Iowa, C. Brown, 1980.

5. FOUCAULT, M. O nascimento da clínica. São Paulo, Forense, 1979.

6. FRAUENTHAL, J. Mathematical modeling in epidemiology. Berlim, Springer-Verlag, 1980.

7. INTERNATIONAL EPIDEMIOLOGICAL ASSOCIATION. The history of the IEA brought up to date. Int. J. Epidemiol., 13 (2): 139-41, 1984.

8. LAST, J. (ed.) A dictionary of epidemiology. New York, Oxford Univ. Press, 1983.

9. LILIENFELD, D.E. \& LILIENFELD, A. The French influence on the development of epidemiology. In: LILIENFELD, A. Times, places and persons. Baltimore, Johns Hopkins Univ. Press, 1980

10. MACMAHON, B. \& PUGH, T. Epidemiology: principles and methods. Boston, Little, Brown \& Co., 1970.

11. NAJERA, E. Usos y perspectivas de la epidemiologia en la investigación. s.n.t. [Trabalho apresentado no Seminário sobre Usos y perspectivas de la Epidemiologia", Buenos Aires, 1983].

12. ORGANIZACION PANAMERICANA DE LA SALUD. Riesgos del ambiente humano para la salud. Washington, 1976. (Publicación Científica, 329).

13. PAVLOVSKY, E. Human diseases with natural foci. Moscou, Ioreign Lang. Publ. House, 1963.

14. ROSEN, G. A History of public health. New York, MD Publ., 1958.

15. SACKETT, D. Bias in analytic research. J. Chron. Dit., 32. $51-63,1979$

16. STALLEYBRASS, C. The principles of Epidemiology. London, Routledge, 1931. Apud LAST, J. (cd.) A dictionary of epide. miology. Oxford, Univ. Press, 1983.

17. STAROBINSKY, J. História da medicina. Lisboa, Morais, 1967.

18. WHITE, K. Letter to the editor. Int. J. Epidemiol., 12 (4): 490-1, 1983. 